\title{
Quality Parameters for commercialized Royal Jelly
}

\author{
Carmen Ioana MUREŞAN, Liviu Alexandru MÃRGHITAȘ, Daniel Severus DEZMIREAN, Otilia BOBIŞ*, \\ Victoriţa BONTA, Iulia ZACHARIAS, Rodica MÃRGÃOAN, Claudia PAŞCA
}

Department of Beekeeping and Sericulture, Faculty of Animal Science and Biotechnologies, University of Agricultural Sciences and Veterinary Medicine Cluj-Napoca, 3-5 Manastur Street, 400372, ClujNapoca, Romania.

*corresponding author, e-mail: obobis@usamvcluj.ro

Bulletin UASVM Animal Science and Biotechnologies 73(1)/ 2016

Print ISSN 1843-5262; Electronic ISSN 1843-536X

DOI:10.15835/buasvmcn-asb:11630

\begin{abstract}
Royal jelly has become a high-value commercial product and the standardization of this product is required to guarantee its quality on the market. The objective of the research activity was to pursue the chemical composition of commercial samples of Royal Jelly in Romania in order to propose standardization for this product. The physicochemical composition of commercial Royal Jelly samples was analysed by determining quality parameters like: carbohydrates, lipids, proteins, 10-hydroxy-2-decenoic acid (10-HDA) and mineral elements. Carbohydrates analysis showed values between $3.4 \%$ and $5.87 \%$ for fructose, $4.12 \%$ and $7.05 \%$ for glucose, while for sucrose the values ranged between $0.95 \%$ and $2.56 \%$ (determined by HPLC-RI). The lipids content ranged between 1.85 $\%$ and $6.32 \%$ (determined by the Soxhlet method). The protein values extended from $13.10 \%$ (RJ2) to 17.04 $\%$ (RJ10) (the total protein content was determined by the Kjeldahl method). The values for the major fatty acid in Royal Jelly, 10-HDA, ranged between $1.35 \%$ (RJ8) and $2.03 \%$ (RJ10) (determined by high-performance liquid chromatography). The concentration of minerals varied between $3188.70 \mathrm{mg} / \mathrm{kg}$ and $4023.39 \mathrm{mg} / \mathrm{kg}$ (the concentration of minerals was measured using flame atomic absorption spectrometry). Potassium, followed by magnesium, sodium and calcium, occurs in the highest concentrations. The commercial Royal Jelly samples analysed presented variable physico-chemical characteristics that correspond with the values given by international quality standard proposals for Royal Jelly.
\end{abstract}

Keywords: minerals, royal jelly, quality parameters, 10-HDA

\section{INTRODUCTION}

Royal Jelly is a heterogeneous substance secreted by the cephalic glands of Apis mellifera $L$. young worker honeybees, nursing the larvae in their first three days, while the honeybee queens continue to be fed with Royal Jelly throughout their entire lives. Royal Jelly (RJ) is a homogeneous product of yellowish colour, viscous and creamy consistency, characteristic odour and a slightly pungent taste (Mărghitaş, 2008). It is a high-priced bee product with a complex composition. It is a matrix of polar nature with a high content of water, while the main constituents are lipids, proteins, carbohydrates, amino acids, enzymes, hormones, vitamins and minerals (Mărghitaş, 2008).

Royal Jelly is a hive product rich in bioactive compounds with various biological properties and effects: antioxidative (Guo et al., 2005, 2009; Jamnik et al., 2007; Silici et al., 2009; DelkhosheKasmaie et al., 2014), antiaging (Inoue et al., 2003), tonic (Fossati, 1972), antimicrobial (Fontana et al., 2004; Romanelli et al., 2011), immunomodulatory (Mannoor et al., 2009), anti-inflammatory (Kohno et al., 2004, 2015), neurotrophic, hypoglicaemic, hypocholesterolaemic (Kamakura et al., 2006; Kashima et al., 2014), vasodilative (Tokunaga et al., 2004), antitumoral, anti-allergic (Okamoto et al., 2003).

The composition of RJ is relatively constant at macro level and varies depending on bee nutrition, bee species, climate, season, harvesting method and the age of the bee larvae (Liu et al., 2008). Due to its composition, RJ represents a key factor in the development of honeybee queens due 
to its potential for increasing fertility, longevity and body size. Worker bees and honeybee queens are genetically identical individuals, which leads to the conclusion that longevity and the different development in the case of honeybee queens is due to the RJ as unique source of nutrition for the honeybee queens. Thus, due to its complex composition, it is considered that the beneficial effects are the result of the synergistic activity and action mechanism of its various constituents and effects that have been studied in recent years.

$\mathrm{RJ}$ can be adulterated by addition of larvae triturate, honey, egg white, yogurt, corn starch, etc. These falsifications lead to changes of moisture, protein, lipids and 10-HDA values (Garcia-Amoedo-Muradian and Almeida, 2009). In the case of adulteration with larvae triturate, the moisture percentage increases, the protein value decreases and the $\mathrm{pH}$ increases, while in the case of egg addition the percentages of lipids and $\mathrm{pH}$ increase (Mărghitaş, 2008).

The European Commission considers standardization as a voluntary cooperation based on consensus between consumers, industry, public authorities and other stakeholders in developing standards. According to the Commission, a characteristic of standardization is the market orientation towards competitiveness by aiming towards cooperation, agreement on test methods, requirements related to security, environment and health, and the organizational framework. National standards have been established in some countries (namely Bulgaria, Switzerland, Japan and Brazil). In 2014, a draft for an international standard for Royal Jelly was submitted by the International Organization for Standardization for voting and comment at an international level and its current status is under development (the ISO document has the reference number ISO/DIS 12824:2014).

Royal Jelly is a bee product with great potential for the industry, especially for the food industry and the pharmaceutical industry, which determines the need for implementing quality parameters and standardization. Thus, the aim of this study was to evaluate the physico-chemical parameters of Royal Jelly that is found and sold on the Romanian market.

\section{MATERIALS AND METHODS}

Samples. The commercial Royal Jelly samples were obtained directly from a beekeeper or pur- chased randomly from six different commercial suppliers. The first five samples were harvested in 2014, and the following five samples in 2011. The samples were stored in hygienic conditions, away from sunlight and at refrigeration temperature until further analysis.

The total protein content was determined by the international reference method, namely the Kjeldhal method according to AOAC. The Royal Jelly samples were weighed (1 g) and subjected to the digestion step using Buchi Digestion Unit K-424 coupled with Buchi B-414 Scrubber. The distillation step was carried out using the KjelFlex K-360 device and for the titration step an automatic titrator (Schott Titroline easy) was used. The results were calculated using the conversion factor of 6.25 ( $\mathrm{N} \times 6.25)$.

Determination of carbohydrates was performed by HPLC-RI analysis (Shimadzu). The sample preparation consisted in weighing 1 $\mathrm{g}$ of RJ sample in a $5 \mathrm{~mL}$ volumetric flask and homogenization with $3 \mathrm{~mL}$ of ultrapure water/ methanol (v/v 3:1). After adding $0.1 \mathrm{~mL}$ Carrez I reagent and $0.1 \mathrm{~mL}$ Carrez II reagent, the flask was filled until $5 \mathrm{~mL}$ with a mixture of ultrapure water/methanol (v/v 3:1). After centrifugation at 4,000 rpm for 30 minutes, the supernatant was collected and washed with dichloromethane for 2-3 minutes, then filtered through Millipore $(0.45$ $\mathrm{mm})$. Then the filtrate was injected on a VP HPLC (100A Amino Altima column of $4.6 \mathrm{~mm}$ diameter, $250 \mathrm{~mm}$ length and $5 \mathrm{~mm}$ particle size). The injection volume of $10 \mathrm{~mL}$ was at a flow rate of 1.3 $\mathrm{mL} / \mathrm{min}$. and a $30{ }^{\circ} \mathrm{C}$ temperature. The calibration curve was obtained by using the following standards: glucose, fructose, sucrose, maltose, turanose, trehalose, erlose and isomaltulose. The results were expressed as percentages.

The lipid content in RJ samples was determined by the Soxhlet method. Diethyl ether was used for extraction. The analysis was carried out using a Soxtherm extraction unit (Soxtherm Gerhardt coupled with Multistat Gerhardt). The results were expressed as percentages.

The 10-hydroxy-2-decenoic acid (10-HDA) content was analysed by HPLC-PDA on a LC-10 AD VP (Shimadzu) using a reverse phase column C-18 Supelcosil of $4.6 \mathrm{~mm}$ diameter, $250 \mathrm{~mm}$ length and $5 \mathrm{~mm}$ particle size. Ultrapure water of $\mathrm{pH} 2.5$ and methanol were used as mobile phases. The samples were weighed $(150 \mathrm{mg}$ ) in a volumetric flask, then 
dissolved with a mixture of methanol: ultrapure water of $\mathrm{pH} 2.5$ (60:40, v/v), and sonicated for 30 minutes. The volumetric flasks containing the sonicated samples were filled until $50 \mathrm{~mL}$ with the mobile phase, then they were centrifuged at 4,000 rpm for 10 minutes and filtered through $0.22 \mu \mathrm{m}$ filters. The volume of injection was $20 \mu \mathrm{L}$ at a flow rate of $1 \mathrm{~mL} / \mathrm{min}$. The detection was performed at $210 \mathrm{~nm}$. For the calibration curve, the standard concentration ranged from 0.2 to $200 \mu \mathrm{g} / \mathrm{mL}$. The $\mathrm{r}^{2}$ coefficient was 0.9999 , indicating a good correlation between the readings. The results were expressed as percentages.

The mineral elements in RJ samples were determined by atomic absorption spectroscopy using the AAnalyst ${ }^{\mathrm{TM}} 800$ (PerkinElmer ${ }^{\circledR}$ ) flame atomic absorption spectrometer equipped with WinLab32. An air-acetylene flame was used to produce the high temperature requirements. For the digestion step, approximately $0.3 \mathrm{~g}$ of homogenized sample was weighed directly into the high pressure digestion vessel PTFE-TFM. 65\% nitric acid ( $2 \mathrm{~mL}$ ) and $30 \%$ hydrogen peroxide (3 $\mathrm{mL}$ ) were added to each sample. The samples were sealed in the ceramic coating and then placed in the Rotor 8XF100. The digestion was carried out using microwaves. The microwave digestion program consisted in three stages:

1) $145^{\circ} \mathrm{C} / 5$ minutes $/ 75 \%$ power;

2) $180^{\circ} \mathrm{C} / 10$ minutes $/ 90 \%$ power;

3) $100^{\circ} \mathrm{C} / 10$ minutes $/ 40 \%$ power.
The digested samples were transferred to $25 \mathrm{~mL}$ volumetric flasks and filled until $25 \mathrm{~mL}$ with ultrapure water. The calibration curves for each element were performed using standards of different concentration from stock solutions.

Statistical analysis. The results were expressed as mean values \pm standard deviations of separate determinations in comparison to the fresh weight. The data was analysed using Microsoft Excel 2010 and Minitab 17 Statistical Software. One-way ANOVA and the Tukey test were performed for the statistical evaluation of the data obtained.

\section{RESULTS AND DISCUSSION}

During storage, changes of RJ quality occur: colour changes due to the oxidation and Maillard reactions, the viscosity and the acidity increase (due to the lipid oxidation), while the enzymatic activity and the carbohydrates content decrease. The characterization of $\mathrm{RJ}$ is relevant for proposing standardization.

According to Sabatini (2009) the estimated lipid content in fresh Royal Jelly is 3-8 \%. The average lipid content in the Royal Jelly samples harvested in 2011 (2.63\%) was lower than that of the samples harvested in 2014 (4.35\%) due to the lipidic fraction degradation during storage (as shown in Fig.1). When the results were analysed using one-way ANOVA and the Tukey test (95\% confidence) the null hypothesis could be rejected

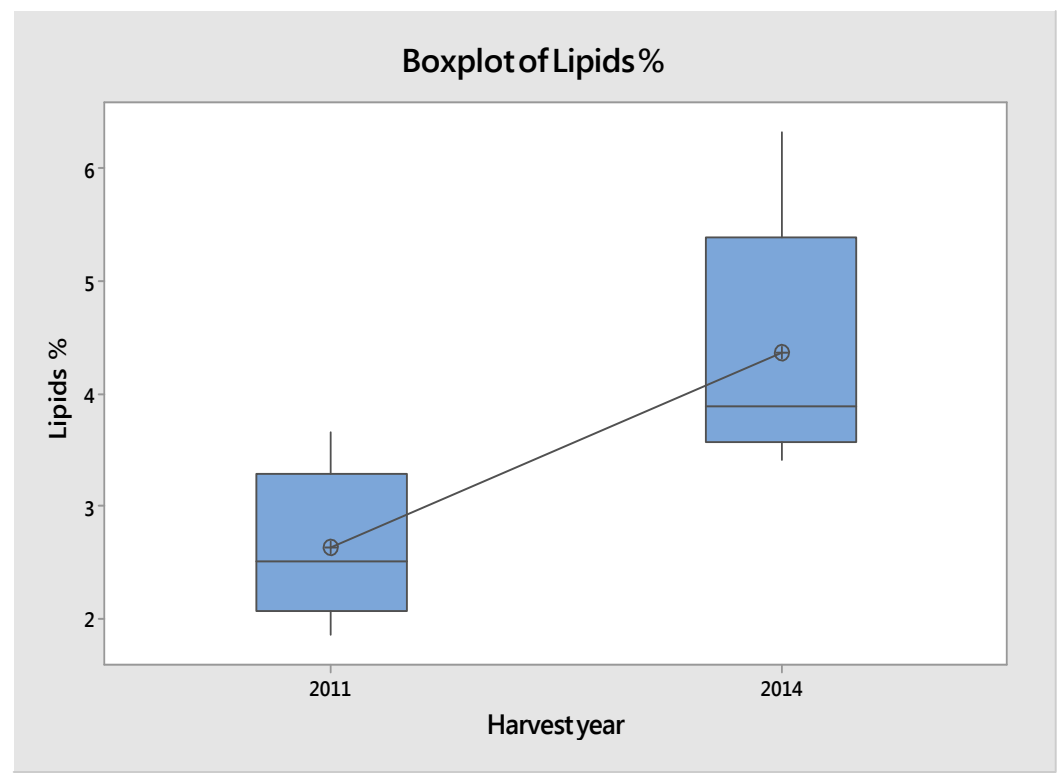

Fig. 1. Boxplot for the percentage of lipids in the Royal Jelly samples 
concluding that the samples from different harvest years were significantly different $(\mathrm{p}<0.05)$. Among the ten analysed samples, six samples (RJ1, RJ2, RJ3, RJ4, RJ5, and RJ7) were between the limits proposed by Sabatini (2009) of 3-8 \%, while the rest were under the minimum limit of $3 \%$. Only one sample harvested in 2011 had a high value of lipid content (3.66\%), which may be due the fact that at the harvest moment it already had been a rich source of lipids.

The protein values in the RJ samples ranged from $13.10 \%$ to $17.04 \%$. Sample RJ10 had the highest total protein content while the sample RJ2 had the lowest percentage. All the studied samples were within the estimated limits of total protein content in fresh RJ of 9-18\% (Sabatini et al., 2009). The results were compared using one-way ANOVA and the significance differences were measured by Tukey method at a significance level of 95\% $(p<0.05)$ as shown in Fig. 2. From the statistical analysis we concluded that the differences between the protein levels in the samples harvested in 2011, and in 2014 are statistically significantly different. The protein content increases during storage in the RJ samples. The protein profile of RJ integrates the MRJPs (Major Royal Jelly Proteins) which comprise approximately $90 \%$ of the total water-soluble Royal Jelly proteins (Albert et al., 1999; Buttstedt et al., 2014).

The major fatty acid in RJ is 10-HDA and it was determined by HPLC. The values ranged between 1.35\% (RJ8) and 2.03\% (RJ10). Recent studies proposed 10-HDA as a freshness indicator but the variation of this fatty acid in the RJ lead to the conclusion that it is challenging to use it as a marker for RJ freshness (Antinelli et al., 2003). However, 10-HDA represents an adulteration indicator and should be above $1.4 \%$ for fresh RJ (Garcia-Amoedo and Almeida-Muradian, 2007; Sabatini et al., 2009). The values for the analysed RJ samples were within the limits proposed by the scientific literature. The statistical analysis for the 10-HDA values using one-way ANOVA and the Tukey test revealed that there is no statistical difference between the Royal Jelly samples as shown in Fig.3 (the p-value of 0.928 is higher than the significance level " $\alpha$-value" of 0.05). The main components of the lipid profile in $\mathrm{RJ}$ are the middle carbon chain fatty acids, 10-HDA being the predominant one among them (Xu and Gao, 2013). The fatty acids in RJ have been investigated and the results showed an estrogenic activity of these compounds (Mishima et al., 2005; Moutsatsou et al., 2010).

Carbohydrates in Royal Jelly are represented by fructose, glucose, sucrose, ribose, mannose, trehalose, erythritol and mannitol (Palma, 1992). The content of carbohydrates in the analysed samples is in agreement with the levels proposed by Sabatini (2009) of 3-13\% for fructose, 4-8 \% for glucose and $0.5-2.0 \%$ for sucrose. The average contents of fructose and glucose are lower for the samples harvested in 2014 as compared to those harvested in 2011, which instead have a higher

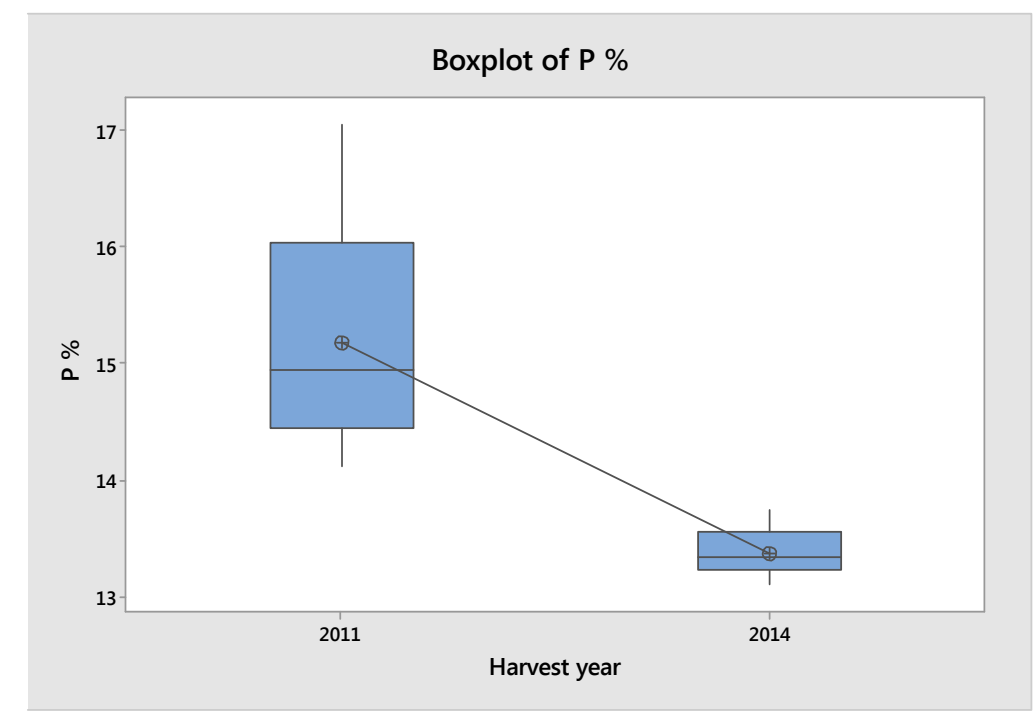

Fig. 2. Boxplot for the percentage of proteins in the Royal Jelly samples 


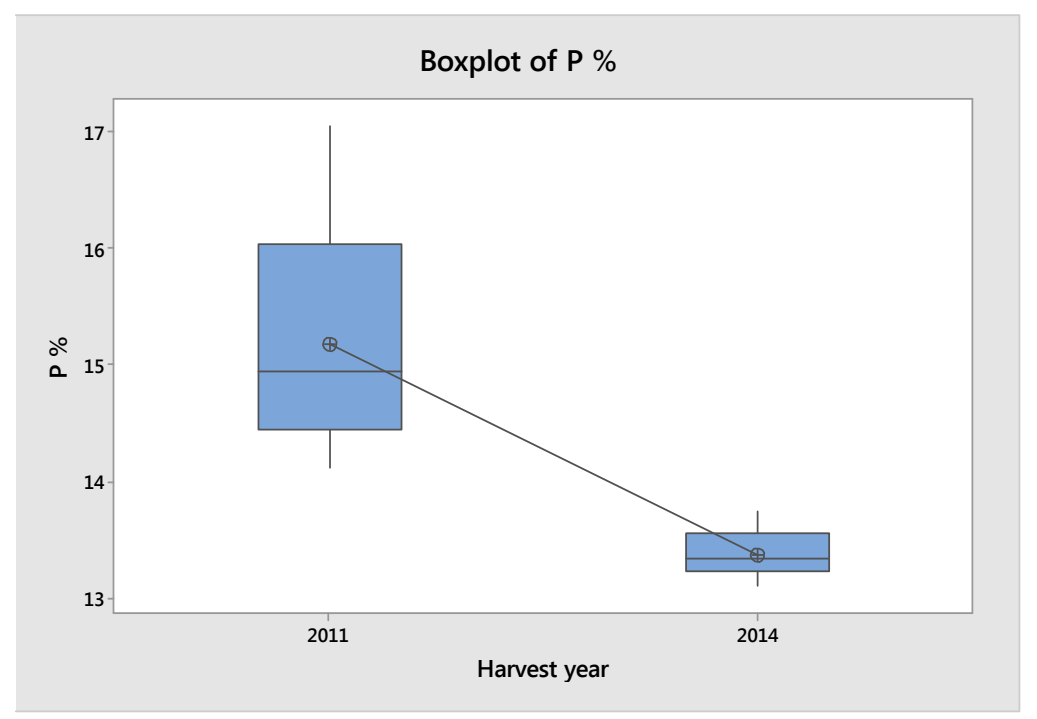

Fig. 2. Boxplot for the percentage of proteins in the Royal Jelly samples

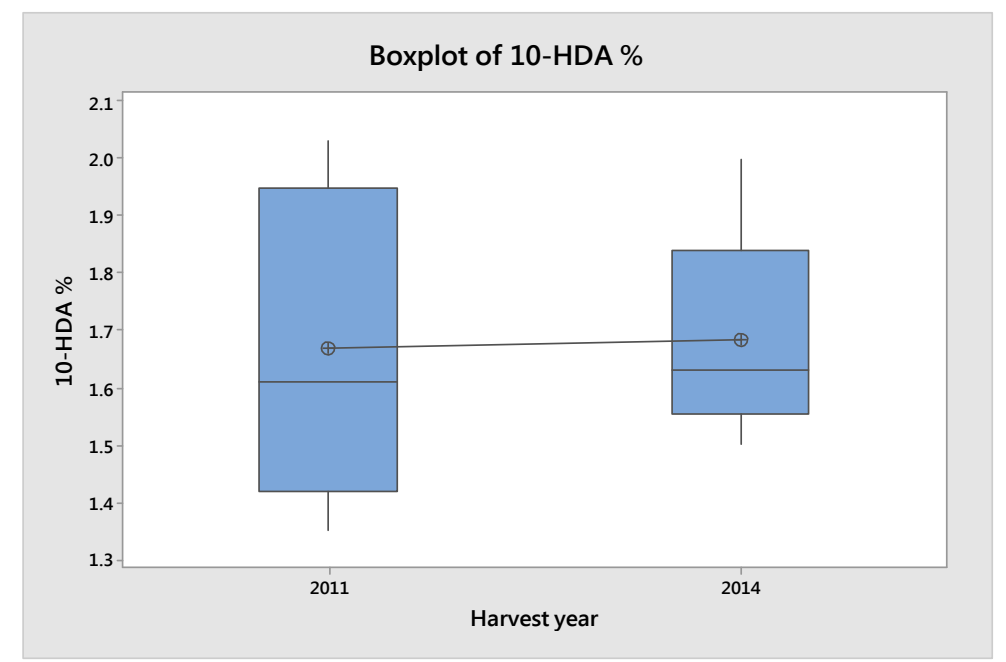

Fig. 3. Boxplot for the percentage of 10-HDA in the Royal Jelly samples

content of sucrose (as shown in Fig.4). The results show that sucrose varies considerably with values between $0.95 \%$ and $2.56 \%$. The statistical analysis for the carbohydrate values using one-way ANOVA and the Tukey test revealed that fructose, glucose and sucrose levels are not significantly different.

Royal Jelly mineral elements content is influenced by internal and external factors, such as honeybee organism mechanisms, environment, feeding quality and production period. RJ has a high content of trace and mineral components with biological role, mainly $\mathrm{Na}, \mathrm{K}, \mathrm{Mg}, \mathrm{Ca}, \mathrm{P}, \mathrm{Fe}, \mathrm{Zn}$, $\mathrm{Cu}, \mathrm{Al}$ and $\mathrm{S}$ (Stocker et al., 2005). The ash content in fresh Royal Jelly reported by scientific research is $0.8-3 \%$ (Sabatini et al, 2009). The content of eight trace and mineral components of our commercial RJ samples was analysed. The most substantial mineral components in commercial RJ were K (2776.81-3517.35 mg/kg), Mg (170.11$213.51 \mathrm{mg} / \mathrm{kg}), \mathrm{Na}$ (107.74-130.72 mg/kg), Ca (82.81-112.17 mg/kg), while the most abundant trace components were $\mathrm{Zn}$ (21.96-27.98 mg/kg) and $\mathrm{Cu}$ (7.64-10.4 mg/kg). Concentrations of $\mathrm{Ca}$, $\mathrm{K}, \mathrm{Mg}$ and $\mathrm{Na}$ were found to be relatively stable in the RJ samples. Trace elements $\mathrm{Cu}, \mathrm{Zn}$ and $\mathrm{Mn}$ also showed stability. The results obtained are presented in Fig.5. 


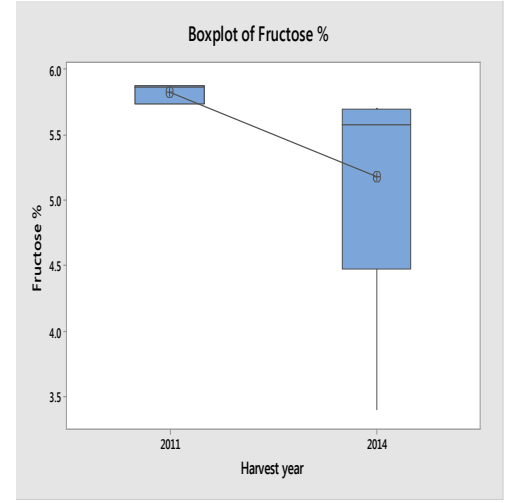

a

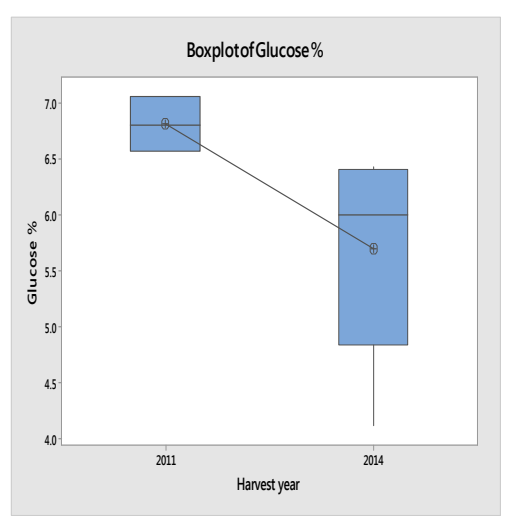

b

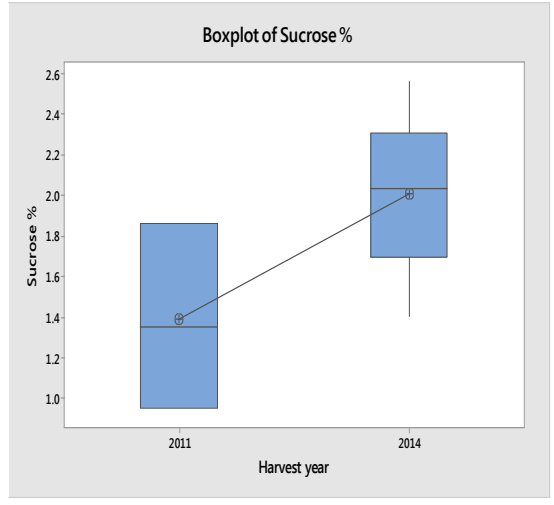

C

Fig. 4. Boxplot for the percentages of fructose (a), glucose (b) and sucrose (c) in the Royal Jelly samples

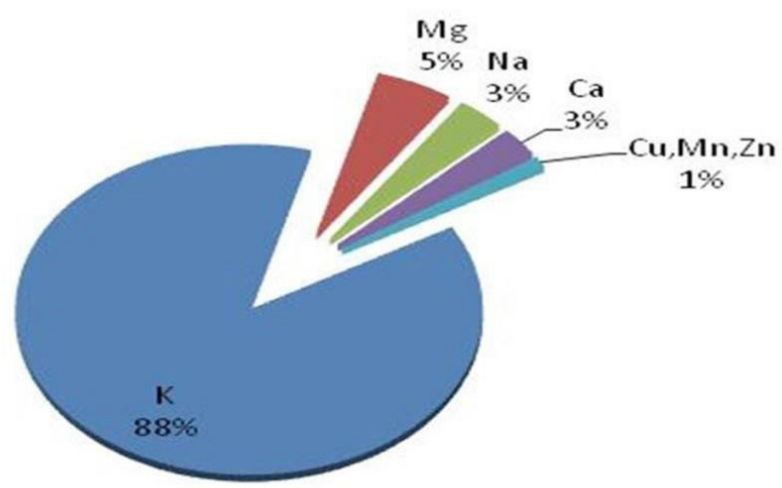

Fig. 5. Percentage of trace and mineral components expressed as total minerals content in ten commercial royal jelly samples
Comparing the values obtained in the samples from 2011 and 2014 (Fig.6), it can be observed that major chemical constituents may have different values, due to different factors. What is the most important is that 10-HDA, considered a freshness and adulteration indicator, is not totally degraded even after 4 years of storage, moreover, it is above the limits proposed by Sabatini et al., (2009), of $1.4 \%$.

\section{CONCLUSION}

Royal Jelly is rich in bioactive compounds with various different biological properties being an exceptional product for the human health. This study reveals a description of RJ from commercial

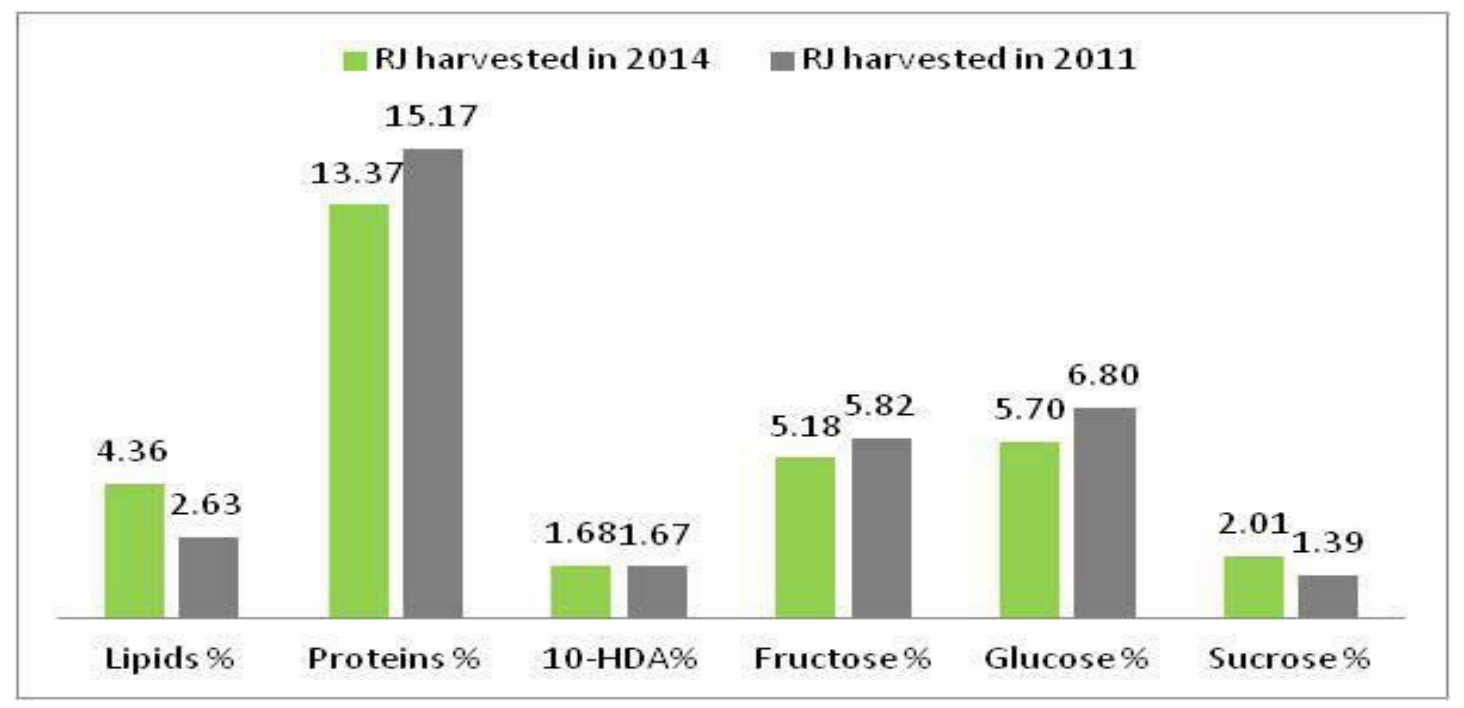

Fig. 6. Lipids, total protein, 10-HDA, fructose, glucose and sucrose content of commercial royal jelly samples. Values are given as means of 5 different samples, analysed in triplicate 
sources in Romania in terms of physico-chemical parameters. Protein, carbohydrates and 10HDA content represent common parameters used to characterize RJ quality. The protein and lipid content were the parameters found to be statistically different between the analysed RJ samples harvested in 2011 and 2014, therefore these parameters may be considered freshness indicators. The levels of lipids in RJ decrease in time due to lipid oxidation, meanwhile the protein content increases during storage. Regarding the mineral elements in RJ from the obtained results, we can conclude that potassium followed by magnesium, sodium and calcium, occurs in the highest concentrations in all RJ samples.

The commercial Royal Jelly samples presented variable physico-chemical characteristics as a result of the changes occurring after long-term storage. Such changes make it appear likely that the biological activity of $\mathrm{RJ}$ is influenced by storage also. These conclusions confirm that a process of standardization of RJ is urgently needed.

Aknowledgements: Financial support was granted by the project Partnerships in Priority Areas Programme - PN II, developed with the support of MEN - UEFISCDI, project no. 148/2014 and POS CCE project RoBeeTech, no. 206/2010

\section{REFERENCES}

1. Albert S, Bhattacharya D, Klaudiny J, Schmitzova J, and Simuth J. (1999). The family of major royal jelly proteins and its evolution. Journal of Molecular Evolution 49: 290297.

2. Antinelli JF, Zeggane S, Davico R, Rognone C, Faucon JP, and Lizzani L. (2003) Evaluation of (E)-10-hydroxydec-2enoic acid as a freshness parameter for royal jelly. Food Chemistry 80: 85-89.

3. Buttstedt A, Moritz RFA, and Erler S. (2014) Origin and function of the major royal jelly proteins of the honeybee (Apis mellifera) as members of the yellow gene family. Biological Reviews 89: 255-269.

4. Delkhoshe-Kasmaie F, Malekinejad H, Khoramjouy M, Rezaei-Golmisheh A, and Janbaze-Acyabar H. (2014) Royal jelly protects from taxol-induced testicular damages via improvement of antioxidant status and up-regulation of E2f1. Systems Biology in Reproductive Medicine 60: 80-88.

5. Fossati C. (1972) Therapeutic possibilities of royal jelly. $L a$ Clinica terapeutica 62: 377-387.

6. Fontana R, Mendes MA, de Souza BM, Konno K, Cesar LMM, Malaspina O, and Palma MS (2004) Jelleines: a family of antimicrobial peptides from the Royal Jelly of honeybees (Apis mellifera). Peptides 25: 919-928.

7. Guo H, Kouzuma Y, and Yonekura M (2005) Isolation and properties of antioxidative peptides from water- soluble royal jelly protein hydrolysate. Food Science and Technology Research 11: 222-230.

8. Guo H, Kouzuma Y, and Yonekura M (2009) Structures and properties of antioxidative peptides derived from royal jelly protein. Food Chemistry 113: 238-245.

9. Inoue $S$, Koya-Miyata $S$, Ushio $S$, Iwaki $K$, Ikeda $M$, and Kurimoto M. (2003) Royal Jelly prolongs the life span of $\mathrm{C} 3 \mathrm{H} / \mathrm{HeJ}$ mice: correlation with reduced DNA damage. Experimental Gerontology 38: 965-969.

10. Jamnik P, Goranovic D, and Raspor P. (2007) Antioxidative action of royal jelly in the yeast cell. Experimental Gerontology 42: 594-600.

11. Kamakura M, Moriyama T, and Sakaki T. (2006) Changes in hepatic gene expression associated with the hypocholesterolaemic activity of royal jelly. Journal of Pharmacy and Pharmacology 58: 1683-1689.

12. Kashima Y, Kanematsu S, Asai S, Kusada M, Watanabe S, Kawashima T,Nakamura T,Shimada M, Goto T, and Nagaoka S. (2014) Identification of a Novel Hypocholesterolemic Protein, Major Royal Jelly Protein 1, Derived from Royal Jelly. Plos One 9.

13. Kohno K, Okamoto I, Sano O, Arai N, Iwaki K, Ikeda M, and Kurimoto M. (2004) Royal jelly inhibits the production of proinflammatory cytokines by activated macrophages. Bioscience Biotechnology and Biochemistry 68: 138-145.

14. Kohno K, Ohashi E, Sano O, Kusano H, Kunikata T, Arai N, Hanaya T, Kawata T, Nishimoto T, and Fukuda S. (2015) Anti-inflammatory effects of adenosine N1-oxide. Journal of Inflammation-London 12.

15. Liu J-R, Yang Y-C, Shi L-S, and Peng C-C. (2008) Antioxidant Properties of Royal Jelly Associated with Larval Age and Time of Harvest. Journal of Agricultural and Food Chemistry 56: 11447-11452.

16. Mannoor MK, Shimabukuro I, Tsukamotoa M, Watanabe H, Yamaguchi K, and Sato Y. (2009) Honeybee royal jelly inhibits autoimmunity in SLE-prone NZB x NZW F1 mice. Lupus 18: 44-52.

17. Mărghitaș LAl. (2008). Albinele și produsele lor, Editura Ceres, București.

18. Mishima S, Suzuki KM, Isohama Y, Kuratsu N, Araki Y, Inoue M, and Miyata T. (2005) Royal jelly has estrogenic effects in vitro and in vivo. Journal of Ethnopharmacology 101: 215-220.

19. Moutsatsou P, Papoutsi Z, Kassi E, Heldring N, Zhao CY, Tsiapara A, Melliou E, Chrousos GP, Chinou I, Karshikoff A, Nilsson L, and Dahlman-Wright K. (2010) Fatty Acids Derived from Royal Jelly Are Modulators of Estrogen Receptor Functions. Plos One 5.

20. Okamoto I, Taniguchi Y, Kunikata T, Kohno K, Iwaki K, Ikeda M, and Kurimoto M. (2003) Major royal jelly protein 3 modulates immune responses in vitro and in vivo. Life Sciences 73: 2029-2045.

21. Palma MS. (1992) Composition of freshly harvested Brazilian royal jelly - identification of carbohydrates from the sugar fraction. Journal of Apicultural Research 31: 4244.

22. Romanelli A, Moggio L, Montella RC, Campiglia $\mathrm{P}$, Iannaccone M, Capuano F, Pedone $\mathrm{C}$, and Capparelli 
R. (2011) Peptides from Royal Jelly: studies on the antimicrobial activity of jelleins, jelleins analogs and synergy with temporins. Journal of Peptide Science 17: 348-352.

23. Sabatini AG, Marcazzan GL, Caboni MF, Bogdanov $S$ and Almeida-Muradian LB. (2009). Quality and standardisation of Royal Jelly. Journal of ApiProduct and ApiMedical Science 1(1): 1-6.

24. Silici S, Ekmekcioglu O, Eraslan G, and Demirtas A (2009) Antioxidative Effect of Royal Jelly in Cisplatin-induced Testes Damage. Urology 74: 545-551.
25. Stocker A, Schramel P, Kettrup A, and Bengsch E. (2005) Trace and mineral elements in royal jelly and homeostatic effects. Journal of Trace Elements in Medicine and Biology 19: 183-189.

26. TokunagaKH,YoshidaC,SuzukiKM,MaruyamaH,Futamura Y, Araki Y, and Mishima S. (2004) Antihypertensive effect of peptides from Royal Jelly in spontaneously hypertensive rats. Biological \& Pharmaceutical Bulletin 27: 189-192.

27. Xu X, and Gao YX. (2013) Isolation and characterization of proteins and lipids from honeybee (Apis mellifera L.) queen larvae and royal jelly. Food Research International 54: 330-337. 